UCRL-JC-131761

Preprint

\title{
Electrical Resistance Tomography of Unsaturated Flow and Transport in Yucca Mountain
}

\author{
M. Buettner, W. Daily, A. Ramirez and G. Bussod
}

This paper was prepared for submittal to

Symposium on the Application of Geophysics to Engineering and Environmental Problems Oakland, CA

March 14-18, 1999

December 28, 1998






\section{DISCLAIMER}

This document was prepared as an account of work sponsored by an agency of the United States Government. Neither the United States Government nor the University of California nor any of their employees, makes any warranty, express or implied, or assumes any legal liability or responsibility for the accuracy, completeness, or usefulness of any information, apparatus, product, or process disclosed, or represents that its use would not infringe privately owned nights. Reference herein to any specific commercial product, process, or service by trade name, trademark, manufacturer, or otherwise, does not necessarily constitute or imply its endorsement, recommendation, or favoring by the United States Government or the University of Califomia. The views and opinions of authors expressed herein do not necessarily state or reflect those of the United States Government or the University of California, and shall not be used for advertising or product endorsement purposes. 


\title{
ELECTRICAL RESISTANCE TOMOGRAPHY OF UNSATURATED FLOW AND TRANSPORT IN YUCCA MOUNTAIN
}

\author{
Michael Buettner \\ William Daily \\ Abe Ramirez \\ Lawrence Livermore National Lab \\ P.O. Box 808 \\ 7000 East Avenue \\ Livermore, CA 94550 \\ Gilles Bussod \\ Los Alamos National Lab \\ Geoanalysis Group - EES 5. \\ Division of Earth and Environmental Sciences \\ TA 3, SM 43 \\ Mail Stop F 665 \\ Los Alamos, NM 87545
}

\begin{abstract}
Electrical Resistance Tomography (ERT), a new geophysical imaging technique, was used to study the movement of a tracer through the test block at the Unsaturated Zone Transport Test (UZTT) at Busted Butte, Nevada. Data were collected four times starting in July and ending in early September, 1998. ERT baseline images show a resistivity structure which is consistent with the known lithology in the rear part of the test block. There appears to be a low resistivity region in the front half of the block, particularly near the bottom. Difference images from August 19 and September 9 show clear and consistent resistivity decreases in the region near injection holes 18 , 20 , and 21 which can be associated with the injection of conductive water. The images show very little effect in the region around the other injection holes, 23, and 24 through 27 where far less water was injected. Difference images from August 19 and September 9 show resistivity decreases which could be interpreted as water moving down into the block. This is the same region which has an anomalously low resistivity in the baseline image. These results should be considered preliminary, and are subject to further interpretation.
\end{abstract}

\section{INTRODUCTION}

In order to evaluate and understand the fundamental processes and uncertainties associated with flow and transport in the unsaturated zone site-scale models for Yucca Mountain, an underground transport test facility was sited, designed, and constructed at Busted Butte, Nevada.

Busted Butte is located in Area 25 of the Nevada Test Site (NTS), approximately $160 \mathrm{~km}$ northwest of Las Vegas, Nevada, and $8 \mathrm{~km}$ southeast of the potential Yucca Mountain repository area. The site was chosen based on the presence of a readily accessible cxposurc of unsaturated rocks of the Topopah Springs/Calico Hills formations and the similarity of these units to those beneath the potential repository horizon.

Electrical Resistance Tomography (ERT), Ground Penetrating Radar (GPR) and neutron logging were used to determine the saturation state of the block prior to and during testing.

The objective of this work is to provide 3d ERT images of the movement of the tracer through the test block at the Unsaturated Zone Transport Test (UZTT) at Busted Butte. ERT was chosen as an appropriate technology based on its success at many other locations including the Drift Scale Test at Yucca Mountain. This report describes the results obtained during 4 separate data collections starting in July and ending in early September, 1998. 


\section{DESCRIPTION OF THE ERT METHOD}

Electrical resistance tomography (ERT) is a new geophysical imaging technique which can be used to map subsurface liquids as flow occurs during natural or man-induced processes and to map geologic structure. Man-induced processes such as tank leaks and clean-up processes such as steam injection can create changes in a rock's electrical properties that are readily measured. Electrical resistance tomography is a technique for reconstruction of subsurface electrical resistivity. The result of such a reconstruction is a 2 or 3 dimensional map of the electrical resistivity distribution underground made from a series of voltage and current measurements from buried electrodes. The ERT approach we follow here relies on detection and mapping of the changes in electrical resistivity associated with the movement of a tracer through the test block at the Unsaturated Zone Transport Test (UZTT).

ERT surveys are performed using a number of electrodes in boreholes and/or at the rock surface to image the resistivity distribution between two boreholes. Using an automatic data collection and switching system, we collect a few hundred electrical resistance measurements. The data is then processed to produce electrical resistivity tomographs using state of the art data inversion algorithms. We use these measurements to calculate tomographs that show the spatial distribution of the subsurface resistivities.

\section{ERT THEORY AND INVERSION ALGORITHMS}

Space does not permit a description of the 2-dimensional and 3-dimensional theory and inversion algorithms here, but good references are available for the 2-d (LaBrecque et al, 1996) and 3-d (LaBrecque et al, 1998) cases.

\section{ERT DATA COLLECTION SYSTEM}

The ERT data collection system is composed of three main parts; a transmitter, a receiver, and a laptop computer to control the system and archive the data. Without getting into a great deal of detail, the action of the system can be briefly describes as follows.

The computer sets the switches in the multiplexer according to a predefined schedule so as to connect the transmitter to a particular electrode pair, and the receiver channels to other electrode pairs. The receiver commands the transmitter to apply current to the selected transmitter electrode pair, and measures the resulting potentials at the other pairs. The data are then sent back to the computer and stored. A new transmitter pair is selected according to the schedule, and the process begins again until all the combinations in the schedule have been used.

\section{RESULTS FROM THE DATA COLLECTIONS OF JULY TO EARLY SEPTEMBER}

ERT data were collected 4 times: July 2, July 14, August 19, and September 9, 1998. The idea was to do comparisons between the baseline condition on July 2 and data collected at later times. We present comparisons between July 2 and August 19 and July 2 and September 9 because the data from July 14 was of questionable quality.

Sixty ERT electrodes were installed in the UZTT test block as shown in Figure 1a. The electrodes were placed in six drilled holes, ERT-1 though ERT-6, and two surface arrays (upper and lower). Holes ERT-3, 4, 5, and 6 and the surface arrays were drilled perpendicular to and from the instrumentation alcove. Holes ERT-1 and 2 were drilled from the main drift. The electrodes were grouped into "boreholes" 1 through 4 as shown in Figure 1b. As is evident, each borehole is Lshaped and contains 15 electrodes. For example, borehole 1 is composed of the 8 electrodes in hole ERT-3 along with the 7 electrodes in the upper-surface array. 


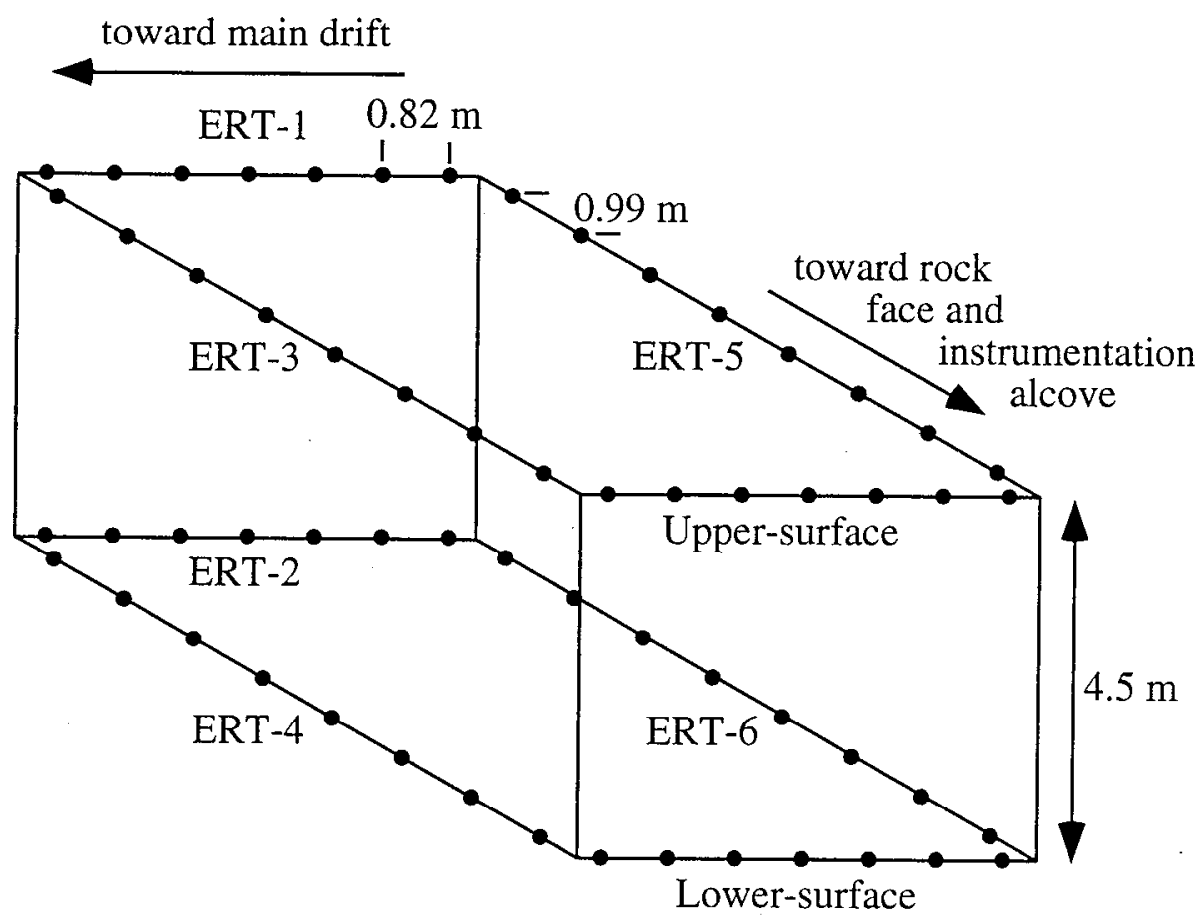

Figure 1a. Layout of drilled holes, ERT electrode locations, and spacing in the UZTT test block at Busted Butte

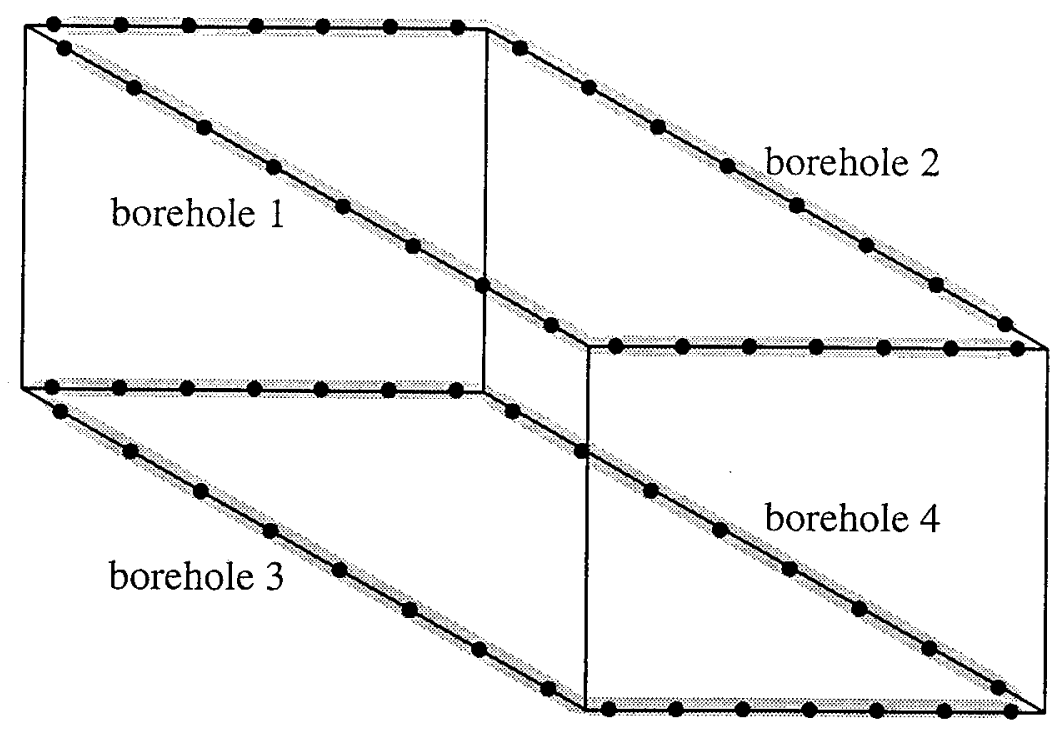

Figure 1b. Grouping of ERT electrodes into "boreholes" in the UZTT test block at Busted Butte 
The ERT data are collected between using borehole pairs. Thus the data are collected between boreholes 1 and 2 (upper horizontal plane), 3 and 4 (lower horizontal plane), 1 and 3 (left vertical plane), 2 and 4 (right vertical plane), 1 and 3 (diagonal), and finally 2 and 4 (diagonal) for a total of six data sets. The total number of data values collected is 2430 . These 2430 values provide the 3 -dimensional sampling of the test block resistivity, and the $3 \mathrm{~d}$ inversion algorithm operates on these data to produce a reconstruction of the $3 \mathrm{~d}$ resistivity distribution, a $3 \mathrm{~d}$ ERT image, of the block.

One could look at absolute ERT images or comparison images. We find it most useful to look at comparison images when changes are taking place over time. The results presented here consider difference images which compare the resistivity of the block on August 19 and September 9 to July 2. Because the water injected during phase 2 of the UZTT experiment was approximately 8 times more conductive than the pore water, we look for resistivity decreases in the images.

\section{ABSOLUTE ERT IMAGES OF THE BLOCK}

Figure 2. shows an absolute image of the July 2 baseline condition (top) and the difference between August 19 and July 2 (bottom). The baseline image shows a layered structure consistent with the lithology in the rear half of the block. That is, a high resistivity layer over most of the middle of the block, Tptpvl, with a lower resistivity region, Tptpv2 at the top, and a low resistivity region, Tac at the bottom. The image also shows an anomalously low resistivity region in the front half of the block, particularly near the bottom.

\section{DIFFERENCE ERT IMAGES OF THE BLOCK}

The Figure 2 difference image shows regions of resistivity decrease near injection holes 18, 20, and 21 as one would expect from the injection of conductive water. One can also see a resistivity decrease which is very pronounced in the slice $2.66 \mathrm{~m}$ from the front of the block, which could be associated with water moving downward in the block. The region of the block between 1.33 and $4.0 \mathrm{~m}$, which contains this slice, also appears to be a resistivity low in the absolute image.

The September 9-July 2 difference image of Figure 3 also shows regions of resistivity decrease near injection holes 18,20 , and 21 . The effect is even stronger in the $5.33 \mathrm{~m}$ slice. Moreover the effect of water moving down into the block seems to be more pronounced in the 1.33 and $4.0 \mathrm{~m}$ slices compared to August 19.

\section{CONCLUSIONS}

The ERT baseline images show a resistivity structure which is consistent with the known lithology in the rear part of the block. There appears to be a low resistivity region in the front half of the block, particularly near the bottom. This is not well-understood, and should be confirmed, if possible, by other means.

The difference images from August 19 and September 9 show clear and consistent resistivity decreases in the region near holes 18,20 , and 21 which can be associated with the injection of conductive water. This effect appears to be stronger on September 9 in the $5.33 \mathrm{~m}$ slice. The images show very little effect in the region around the other injection holes, 23, and 24 through 27 where far less water was injected.

In addition the difference images from August 19 and September 9 show resistivity decreases which could be interpreted as water moving down into the block between the 1.33 and $4.0 \mathrm{~m}$ slices. This is the same region which has an anomalously low resistivity in the baseline image. 


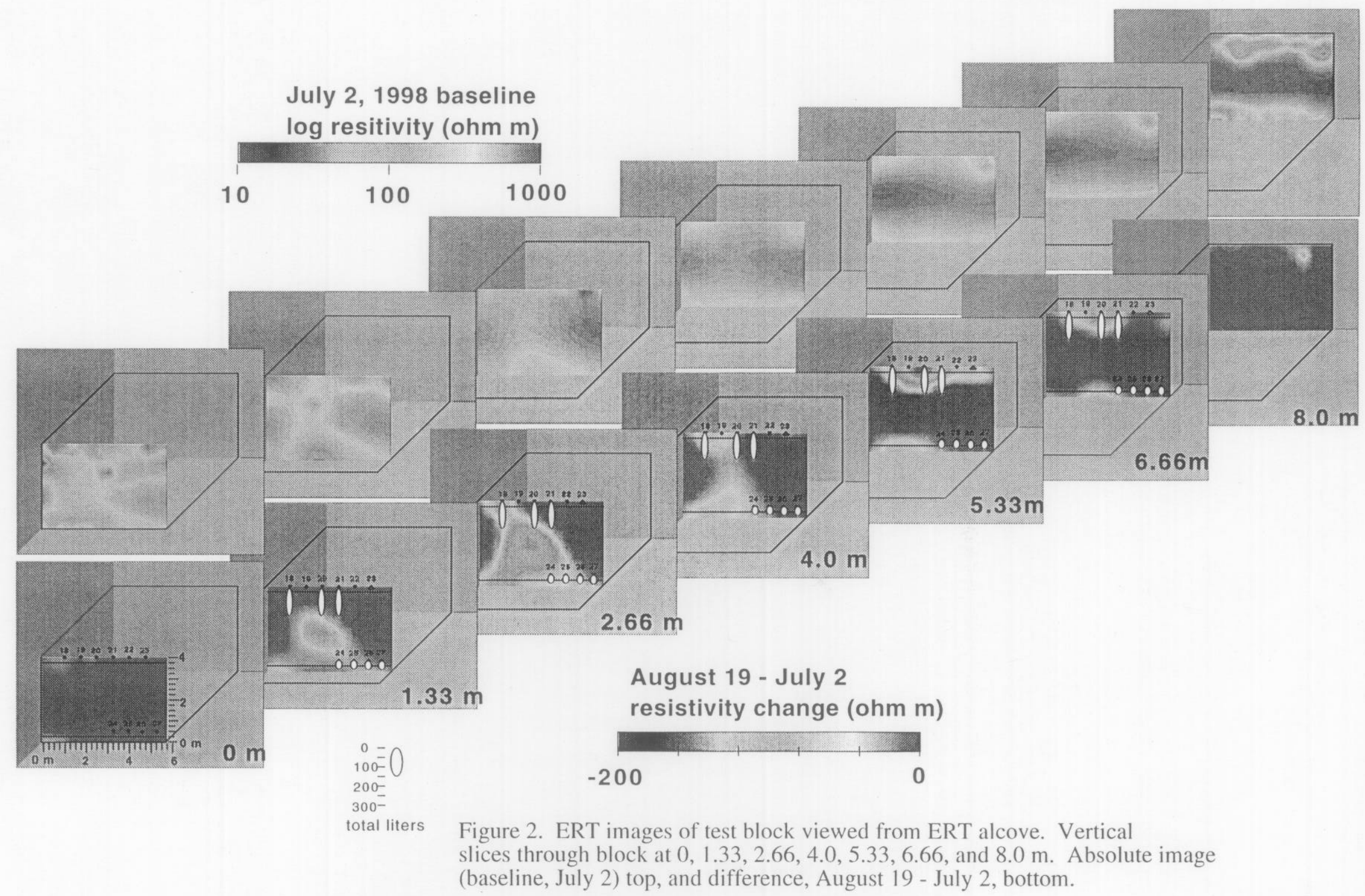




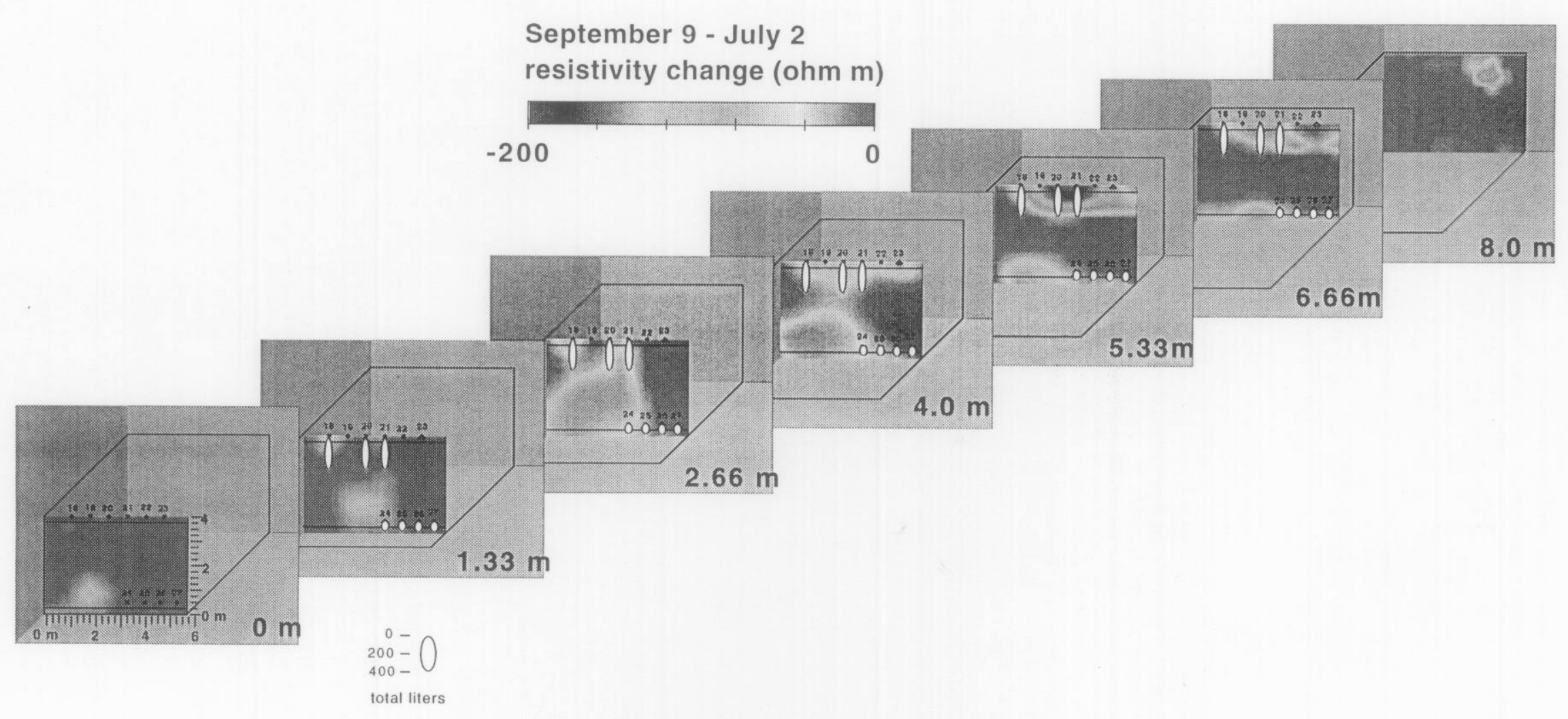

Figure 3. ERT images of test block viewed from ERT alcove.

Vertical slices through block at $0,1.33,2.66,4.0,5.33,6.66$, and

$8.0 \mathrm{~m}$. Difference image, September 9 - July 2. 
These results should be considered preliminary, and subject to change based on new information such as ERT or borehole radar data.

*This work was performed under the auspices of the U.S. Department of Energy by Lawrence Livermore National Laboratory under contract No. W-7405-Eng-48.

\section{REFERENCES}

LaBrecque, D. J., Miletto, M., Daily, W., Ramirez, A., and Owen, E., The effects of noise on Occam's inversion of resistivity tomography data: Geophysics, 61, 538-548, 1996.

LaBrecque, D. and G. Morelli, W. Daily, A. Ramirez, P. Lundegard, Occams inversion of 3D electrical resistivity tomography, in press, in Three Dimensional Electromagnetics, editors, M. Oristaglio, and B. Spies, Society of Exploration Geophysicists, 1998.Bard, Y., 1974, Nonlinear Parameter Estimation (Academic Press, New York), pp. 111-113. 